\title{
In-Hospital Cost Comparison of Transcatheter Closure versus Surgical Closure of Secundum Atrial Septal Defect
}

\author{
Emre Özdemir, Eser Variş¹, Tuncay Kiriş, Sadik Volkan Emren, Cem Nazli, Mehmet Tokaç \\ Cardiology Clinic, Katip Celebi University, Atatürk Education and Research Hospital, Izmir, ${ }^{1}$ Cardiology Clinic, Dr. Burhan Nalbantoğlu Goverment Hospital, Lefkosa, \\ Turkish Republic of Northern Cyprus
}

\section{Abstract}

Introduction: We compared transcatheter and surgical closure of secundum atrial septal defects (ASDs) in terms of cost in this study. Materials and Methods: Between 2006 and 2015, 291 consecutive patients having secundum ASD, in whom percutaneous or surgical closure was performed, were included in this study. We compared the in-hospital cost of transcatheter versus surgical ASD closure in these patients. Results: We collected totaly 291 patients, 214 transcatheter and 77 surgical closure procedures, retrospectively. Patients with a surgical closure had a longer length of stay $(11.8 \pm 3.8$ days vs. $2.8 \pm 1.6$ days, $P<0.001)$. There was no in-hospital mortality in two groups. Costs denominated in Turkish lira (TL) and United States Dollar (USD) of transcatheter closure were higher than that of surgical closure (TL $10955.6 \pm 183.4$ vs. TL $6016.7 \pm 371.9 P<0.001$; USD $6531.2 \pm 149.62$ vs. USD $3896.2 \pm 234.7 P<0.001$ ). The cost of percutaneous ASD closure increase does not correlate with the dollar rate on the annual basis. This with the supplier firms has excessive profits in the first year of the study. Conclusion: Compared with other countries with regard to cost, transcatheter ASD closure is a more expensive treatment than surgical closure in our country.

Keywords: Cardiac surgical procedures, cost analysis, ostium secundum atrial septal defect, septal occluder device

\section{INTRODUCTION}

Atrial septal defects (ASDs) are among the most common congenital heart disease. ${ }^{[1]}$ ASD can be closed either surgically or with a transcatheter device; however, transcatheter strategy as a less invasive procedure, it has become the accepted treatment in patients with appropriate anatomy. ${ }^{[2]}$ The outcomes of percutaneous ASD closures have been compared with surgical closures. It has been shown that transcatheter ASD closure is as effective as the surgical ASD closure. ${ }^{[3,4]}$ Since transcatheter closure is commonly used in ASD, it is important to examine its cost as an important dimension of comparative effectiveness. Many small studies have previously reported that ASD closure is generally associated with lower hospital costs than that of surgical ASD closure. ${ }^{[5-7]}$ However, recently, it has been shown that surgical or transcatheter ASD closure has diversity regarding hospital costs between individual centers. ${ }^{[8]}$ We aimed to compare the costs of transcatheter and surgical ASD closure in Turkey.

\begin{tabular}{|l|l|}
\hline \multicolumn{2}{|c|}{ Access this article online } \\
\hline Quick Response Code: & Website: \\
& \\
http:/www.ijcva.com
\end{tabular}

\section{Materials and Methods}

This is a retrospective study that included patients with a diagnosis of secundum ASD who were treated by transcatheter occlusure or surgical closure between December 2006 and September 2015. Our study's Ethics Committee and Institutional approval were obtained from Izmir Katip Çelebi University. For a proper cost evaluation, ASD patients with other concomitant congenital anomalies and those who underwent additional procedures such as percutaneous transcatheter coronary intervention, coronary bypass surgery, or valve operation were excluded from this study. Therefore, 214 patients with transcatheter closure and 77 patients with surgical closure were included in the study. Patient demographics, hospital length of stay (LOS),

Address for correspondence: Dr. Emre Özdemir, Izmir Katip Celebi University Ataturk Education and Research Hospital, Cardiology, Basin Sitesi, Karabaglar-Izmir 35360, Turkey. E-mail: emreozdemir27@yahoo.com.tr

This is an open access journal, and articles are distributed under the terms of the Creative Commons Attribution-NonCommercial-ShareAlike 4.0 License, which allows others to remix, tweak, and build upon the work non-commercially, as long as appropriate credit is given and the new creations are licensed under the identical terms.

For reprints contact: reprints@medknow.com

How to cite this article: Özdemir E, Variş E, Kiriş T, Emren SV, Nazli C, Tokaç M. In-Hospital cost comparison of transcatheter closure versus surgical closure of secundum atrial septal defect. Int J Cardiovasc Acad 2018;4:28-31. 
and total charges were evaluated using the hospital records. The complaints on application or presenting symptoms were dyspnea, palpitation, recurrent stroke, and chest pain. Concomitant valve diseases were mild-to-moderate pulmonary regurgitation/stenosis, tricuspid regurgitation, and mitral regurgitation.

The percutaneous ASD closure procedure was performed under general anesthesia using ASD closure device in accordance with the techniques described in the literature. ${ }^{[9]}$ The patients undergoing surgical treatment were operated under general anesthesia using the standard approach. The right atrium was opened following median sternotomy, and the ASD was closed with a primary suture or pericardial patch under cardiopulmonary bypass. Only one patient underwent a minithoracotomy without sternotomy. The patients were fully informed of the treatment options, which were decided on with the heart team and patients.

Bleeding complications were divided into two categories. Major bleeding was defined as the need for transfusion of $>2$ units of erythrocyte suspension; otherwise, it was minor bleeding. Minimal leakage was defined as leakage without associated hemodynamic complications.

The cost data were obtained directly from the accounting and resource departments of our hospital. This is a government hospital; there are no items invoiced from outside, and all cost items are invoiced to a reimbursement agency. All prices were calculated in Turkish lira (TL) and converted to the United States dollars (USD) based on the exchange rate given by the Central Bank of the Republic of Turkey on the invoice date. ${ }^{[10]}$ Considering the cost analysis of the study, the period from the day of the patients' hospitalization to the day when they were discharged was assessed. In terms of the study perspective, our work is a direct cost analysis based on the reimbursement agency (Social Security Institution).

\section{RESULTS}

Of 291 of the included patients, 214 underwent transcatheter procedures and 77 underwent surgical closure. The baseline clinical and demographic characteristics of the two groups are demonstrated in Table 1. There was no difference in terms of sex, age, or comorbidities between the two groups. The presenting symptoms were similar in the groups. The surgical closure group had longer LOS $(11.8 \pm 3.8$ days vs. $2.8 \pm 1.6$ days, $P<0.001)$. There was no in-hospital mortality in either groups. The number of concomitant valve diseases was higher in the surgery group $(P<0.05)$ [Table 1].

Periprocedural complications are presented in Table 2. Minimal leakage after the procedure was seen in $7 \%$ of the patients treated with transcatheter closure. Device embolization was observed in three patients, and reintervention was performed. Dehiscence was seen in three patients after the procedure, and surgery was performed in these patients. In addition, 78\% of the transcatheter patients underwent balloon sizing. The

\begin{tabular}{|c|c|c|c|}
\hline Variable & $\begin{array}{c}\text { Transcatheter ASD } \\
\text { closure }(n=214)\end{array}$ & $\begin{array}{l}\text { Surgical ASD } \\
\text { closure }(n=77)\end{array}$ & $P$ \\
\hline Age (years) & $36.5 \pm 14.7$ & $33.2 \pm 13.8$ & 0.082 \\
\hline Sex (male/female) & $68 / 146$ & $20 / 57$ & 0.400 \\
\hline $\begin{array}{l}\text { Hypertension, } \\
n(\%)\end{array}$ & $28(13)$ & $6(7)$ & 0.197 \\
\hline $\begin{array}{l}\text { Diabetes mellitus, } \\
n(\%)\end{array}$ & $9(4)$ & $2(2)$ & 0.507 \\
\hline $\begin{array}{l}\text { Chronic renal } \\
\text { failure, } n(\%)\end{array}$ & $1(0.4)$ & 0 & 0.544 \\
\hline \multicolumn{4}{|l|}{$\begin{array}{l}\text { Complaint on } \\
\text { application, } n(\%)\end{array}$} \\
\hline Dyspnea & $100(45)$ & $48(59)$ & 0.094 \\
\hline Palpitation & $44(20)$ & $18(22)$ & \\
\hline Recurrent stroke & $2(1)$ & 0 & \\
\hline Chest pain & $2(1)$ & 0 & \\
\hline
\end{tabular}

\begin{tabular}{|c|c|c|c|}
\hline Variable & $\begin{array}{l}\text { Transcatheter } \\
\text { ASD closure- } \\
(n=214), n(\%)\end{array}$ & $\begin{array}{c}\text { Surgical ASD } \\
\text { closure- }(n=77), \\
n(\%)\end{array}$ & $P$ \\
\hline Periprocedural shunt & $15(7)$ & 0 & 0.016 \\
\hline Bleeding & $4(1.4)$ & $50(61)$ & $<0.01$ \\
\hline Pleural effusion & 0 & $2(2.4)$ & 0.065 \\
\hline Pericardial effusion & $6(3)$ & $11(14)$ & $<0.01$ \\
\hline Pneumothorax & 0 & $2(2.4)$ & 0.019 \\
\hline Arrhythmia & $5(2.4)$ & 0 & 0.393 \\
\hline Repeat operation & $1(0.4)$ & 0 & 0.544 \\
\hline
\end{tabular}

ASD: Atrial septal defect

Amplatzer occluder device was used in 55\%, Cardi-O-Fix occluder device was used in $42 \%$, and BioSTAR occlude device was used in $3 \%$ of the patients. The surgical closure was performed with primary suture in 53\%, and patch usage for closure was in $47 \%$ of patients. Both major and minor bleeding were more common in the surgery closure group than in the percutaneous closure group ( $9 \%$ vs. $3 \%, P<0.05$ and $5 \%$ vs. $0 \%, P<0.05$, respectively). The rate of pneumothorax requiring surgical intervention was higher in patients treated with surgery [Table 2].

The procedural success rate was similar between the percutaneous closure and surgical closure groups (95\% vs. $99 \%, P=0.139$ ). In this study, the cost of transcatheter closure, denominated in TL and USD, was higher than that of surgical closure (TL $10955.6 \pm 183.4$ vs. TL $6016.7 \pm 371.9, P<0.001$; USD $6531.2 \pm 149.62$ vs. USD $3896.2 \pm 234.7, P<0.001$ ) [Figures 1 and 2]. The increase in the cost of percutaneous ASD closure did not correlate with the USD/TL exchange rate on an annual basis.

\section{Discussion}

Following the first percutaneous ASD closure procedure, parallel to the developing technology, this technique has become an alternative to surgical therapy in the appropriate 


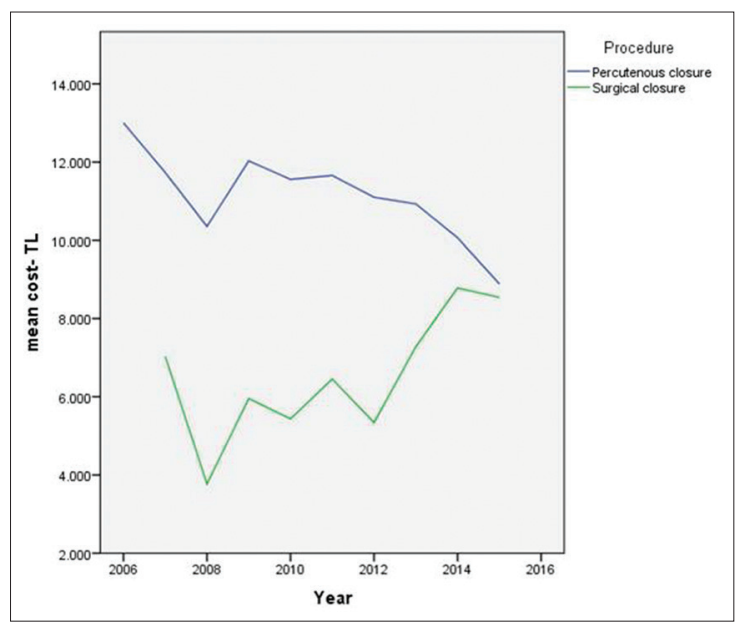

Figure 1: Turkish Lira (TL) based cost change over years in both surgical and transcatheter closure

direction. ${ }^{[1]}$ The outcomes of percutaneous ASD closure have been compared with those of surgical closure. It has been shown that transcatheter ASD closure is as effective as surgical ASD closure ${ }^{[3,4]}$ However, the results of cost-effectiveness analysis for ASD closure are still considered controversial. In a Guatemalan study by Vida et al. ${ }^{[12]}$ surgery costs 3.330 USD, while percutaneous closure costs 4.521 USD. Moreover, in Thomson et al.' ${ }^{[5]}$ study from the United Kingdom, the surgical procedure cost was 5375 Sterling, while the percutaneous procedure cost was 5.412 Sterling. Conversely, a study carried out in the United States, by O'Byrne et al., ${ }^{[13]}$ reported that the cost of operative closure was 60.992 USD, while that of transcatheter closure was 55.841 USD. From the USA again, Ooi et al. ${ }^{[14]}$ reported that the costs of the transcatheter procedure were lower than those of surgical closure (mean of 19.128 USD vs. 25.359 USD). In a Canadian study, Mylotte et al. ${ }^{[7]}$ reported that the cost of surgical closure costs 15.304 Canadian Dollars, while it costs 11060 Canadian Dollars for the transcatheter closure group.

Based on the previous studies, transcatheter closure has lower costs compared with surgical closure. However, from Turkey, Ayık et al.$^{[15]}$ reported that the median cost was significantly higher in the percutaneous group (10.698 TL vs. 5.572 TL). In this study, we found that the cost of transcatheter closure was higher than that of surgical closure (TL 10.955.6 \pm 183.4 TL vs. 6.016.7 \pm 371.9 TL, $6.5312 \pm 14962$; USD vs. $3.896 .2 \pm 234.7$ USD, $P<0.001)$. The most noticeable finding was that, while the USD/TL exchange rate increased from 2006 to 2015, the cost denominated in TL for ASD closure devices did not increase concordantly.

Transcatheter closure has a higher price than surgical closure because an imported device is not used in the surgical option, and the operation fee is the main cost. For transcatheter closure, the main cost is the imported device for this procedure. However, in both surgical and transcatheter closures the fee paid to doctors for the operation is too low, i.e. $20 \%-25 \%$ of the total cost. To import an ASD occluder device depends to foreign exchange

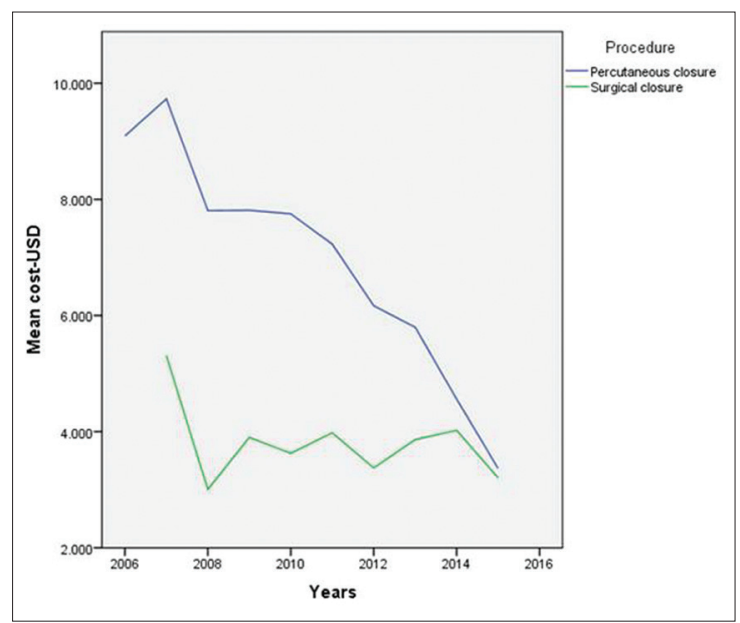

Figure 2: United States dollar (USD) based cost change over years in both surgical and transcatheter closure

rate, and the low value of the TL in foreign exchange is the first reason for the high prices in Turkey; the other and most noticeable reason is that, while the USD/TL exchange rate had been increasing from 1.03 to 3.03 in 2006-2015, the TL-based transcatheter ASD closure versus surgical ASD closure costs were as nearly the same. This shows that importer companies had high profits in the first few years [Figures 1 and 2].

\section{Study limitations}

Even in prospective studies, because the earnings of people can be in very large spectrum, it is difficult to standardize the cost of lost work. This is a short-term and retrospective study, so the main limitation of our study is that we could not reach the datas about patients' cost of labor loss. Therefore, we cannot know whether the cost difference between surgical and percutaneous ASD closure will be different in the long-term period.

\section{ConcLusion}

Compared with the europian countries, the high cost of imported closure devices and supplier firms' high profit rates in the percutaneous group conversely for the surgical group, lower doctor fees in Turkey and no need to imported device, in Turkey surgical closure becomes more cost-effective than transcatheter closure.

\section{Acknowledgment}

All procedures were done with the patient's approval and all authors declare that they were not involved in any conflict of interest.

\section{Financial support and sponsorship}

Nil.

\section{Conflicts of interest}

There are no conflicts of interest.

\section{References}

1. Marelli AJ, Mackie AS, Ionescu-Ittu R, Rahme E, Pilote L. Congenital heart disease in the general population: Changing prevalence and age 
distribution. Circulation 2007;115:163-72.

2. Krasuski RA, Bashore TM. The emerging role of percutaneous intervention in adults with congenital heart disease. Rev Cardiovasc Med 2005;6:11-22.

3. Hughes ML, Maskell G, Goh TH, Wilkinson JL. Prospective comparison of costs and short term health outcomes of surgical versus device closure of atrial septal defect in children. Heart 2002;88:67-70.

4. Kotowycz MA, Therrien J, Ionescu-Ittu R, Owens CG, Pilote L, Martucci G, et al. Long-term outcomes after surgical versus transcatheter closure of atrial septal defects in adults. JACC Cardiovasc Interv 2013;6:497-503.

5. Thomson JD, Aburawi EH, Watterson KG, Van Doorn C, Gibbs JL. Surgical and transcatheter (Amplatzer) closure of atrial septal defects: A prospective comparison of results and cost. Heart 2002;87:466-9.

6. Baker SS, O'Laughlin MP, Jollis JG, Harrison JK, Sanders SP, Li JS, et al. Cost implications of closure of atrial septal defect. Catheter Cardiovasc Interv 2002;55:83-7.

7. Mylotte D, Quenneville SP, Kotowycz MA, Xie X, Brophy JM, Ionescu-Ittu R, et al. Long-term cost-effectiveness of transcatheter versus surgical closure of secundum atrial septal defect in adults. Int $\mathrm{J}$ Cardiol 2014;172:109-14.

8. Pasquali SK, Jacobs ML, He X, Shah SS, Peterson ED, Hall M, et al.
Variation in congenital heart surgery costs across hospitals. Pediatrics 2014;133:e553-60

9. Wilkinson JL, Goh TH. Early clinical experience with use of the 'Amplatzer septal occluder' device for atrial septal defect. Cardiol Young 1998;8:295-302.

10. Available from: http://www.tcmb.gov.tr/kurlar/kurlar tr.html.

11. Faella HJ, Sciegata AM, Alonso JL, Jmelnitsky L. ASD closure with the Amplatzer device. J Interv Cardiol 2003;16:393-7.

12. Vida VL, Barnoya J, O'Connell M, Leon-Wyss J, Larrazabal LA, Castañeda AR, et al. Surgical versus percutaneous occlusion of ostium secundum atrial septal defects: Results and cost-effective considerations in a low-income country. J Am Coll Cardiol 2006;47:326-31.

13. O'Byrne ML, Gillespie MJ, Shinohara RT, Dori Y, Rome JJ, Glatz AC, et al. Cost comparison of transcatheter and operative closures of ostium secundum atrial septal defects. Am Heart J 2015;169:727-3500.

14. Ooi YK, Kelleman M, Ehrlich A, Glanville M, Porter A, Kim D, et al. Transcatheter versus surgical closure of atrial septal defects in children: A value comparison. JACC Cardiovasc Interv 2016;9:79-86.

15. Ayik MF, Işik O, Akyüz M, Kiliç AÖ, Karakuş E, Levent E, et al. Costeffectiveness analysis between surgical and percutaneous closure of atrial septal defects. Nobel Med 2015;11:33-6 